\title{
Cardiovascular Surveys in Areas with Different Water Supplies
}

\author{
P. C. ELWOOD, \\ P. SWEETNAM \\ D. BAINTON, F. MOORE, \\ D. F. DAVIES, \\ E. J. WAKLEY, \\ M. LANGMAN,
}

British Medical fournal, 1971, 2, 362-363

\begin{abstract}
Summary
Cardiovascular surveys were conducted in areas with different water supplies. In two areas with hard water 243 men were seen and in three areas with soft water 357 men were seen. There was no evidence of an important difference between the two areas in blood pressure, serum cholesterol, blood sugar, or packed cell volume. A variety of measurements were made on an E.C.G. The $P-R$ interval was significantly longer in the men in the hard water area, and a 40-complex trace showed ventricular extrasystoles in a significantly higher proportion of these men than in those in the soft water area.
\end{abstract}

\section{Introduction}

An association between water hardness and cardiovascular mortality has been detected in many countries (Kobyashi, 1957; Schroeder, 1960; Crawford, Gardner, and Morris, 1968). Areas with a hard water supply appear to have a lower death rate from all cardiovascular diseases, or from individual causes in this group, than areas with a soft water supply.

If there is a real association between water supply and mortality it could arise in several ways. Firstly, the level of one or several of the known "risk factors" such as blood pressure, serum cholesterol, or packed cell volume could differ in different areas. Secondly, the level of excitability of the myocardium could vary, so that in soft water areas ventricular fibrillation would occur more readily either spontaneously or after infarction. Thirdly, some process relevant to intravascular thrombosis, such as platelet aggregation, fibrin deposition, or fibrinolysis, could be affected.

We are conducting a series of epidemiological studies to examine each of these possible mechanisms so far as is possible in field studies. This paper presents some preliminary findings from a small pilot survey conducted in areas with different water supplies in South Wales. The mortality rates in these areas show differences which are consistent with the differences in the hardness of their water supplies (Hart, 1970).

\section{Method}

Five areas were selected. Two of these have hard water supplies (250-270 p.p.m. and 350-380 p.p.m. total hardness) and three a

M.R.C. Epidemiology Unit, Cardifi CF2 3AS

P. C. ELWOOD, M.D., Member of Scientific Staff

D. BAINTON, M.R.C.P., Member of Scientific Staft

F. MOORE, S.R.N., Member of Scientific Staft

P. SWEETNAM, M.SC., Member of Scientific Staff

West Wales Hospital, Carmarthen

D. F. DAVIES, M.R.C.PATH., Pathologist

General Hospital, Nottingham

E. J. WAKLEY, M.B., M.R.C.P., Medical Research Fellow

M. LANGMAN, M.D., M.R.C.P., Reader, Department of Medicine soft water supply (all around 30-50 p.p.m.). So far as could be ascertained the water supply to these areas had not changed substantially for at least 30 years. Within these areas small villages which seem to be fairly similar were chosen. Electoral rolls were used as a sampling frame and all men over the age of 20 years were invited to co-operate, though in one of the soft water areas only men over 40 years of age were included. Men who were subsequently found to have lived for less than two years in one of the defined areas were omitted. Surveys were conducted during the period May-September and the order of clinics held in soft and hard water areas was haphazard throughout. The times during the day when subjects were seen was the same in all the areas, so the effects of circadian changes in variables can be assumed to be balanced between the areas.

Subjects were asked to fill in a questionnaire which included questions on angina of effort (closely similar to those of Rose, 1962), questions about dyspnoea and the production of phlegm, and details about tobacco smoking. Height and weight were measured and used to derive the standardized index (weight/ height $^{2} \times 10^{4}$ ) of Khosla and Lowe (1967) and blood pressure was measured with a conventional sphygmomanometer. A venous blood sample was used to estimate packed cell volume, serum cholesterol, random blood sugar, and the red cell electrophoretic mobility in plasma (R.E.M.P. $\mu / \mathrm{sec} / \mathrm{V} / \mathrm{cm}$ ). This last is an estimate of the surface charge on suspended red cells and has been found to be reduced in patients who have had a myocardial infarction (Davies, 1958; Begg, Wade, and BronteStewart, 1966). An E.C.G. was used to derive a variety of measurements, including Q-T interval, and a 40-complex strip of lead II was examined for extrasystoles of ventricular origin.

\section{Results}

The results are summarized in Tables I and II. In general, differences between the areas are very small and unlikely to be clinically important. The data were examined in considerable detail, within each of the five areas separately, and within three age groups-under 40 years, 40-64, and 65 and over. There was no evidence of any consistent differences between the variables in the hard and soft water areas, except that a higher proportion of extrasystoles and a longer P-R duration were detected in the E.C.G.s of those living in the hard water areas. The longer P-R interval was separately detected in all three age groups, but the difference in the proportion of men with extrasystoles was not consistent in all the age groups.

TABLE I-Percentage ( \pm S.E.) of Subjects with Symptoms, etc., in the Two Groups

\begin{tabular}{|c|c|c|c|}
\hline & & $\begin{array}{l}\text { Hard Water Areas } \\
(250-380 \text { p.p.m. })\end{array}$ & $\begin{array}{l}\text { Soft Water Areas } \\
\text { (30-50 p.p.m.) }\end{array}$ \\
\hline $\begin{array}{llll}\text { Number } & \ldots & \ldots & \ldots \\
\text { Age (years) } \\
\text { Standardized }\end{array}$ & $\begin{array}{l}. \\
\because\end{array}$ & $\begin{array}{l}47 \cdot 9 \stackrel{243}{ \pm} 0 \cdot 4 \\
25\end{array}$ & 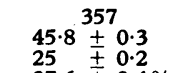 \\
\hline 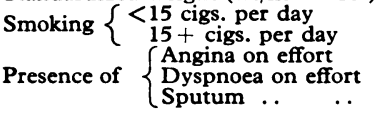 & $\begin{array}{l}\because \\
\therefore \\
\therefore\end{array}$ & $\begin{array}{r}20.5 \pm 2.6 \% \\
26.1 \pm 2.9 \% \\
8.5 \pm 1.8 \% \\
10.6 \pm 2.0 \% \\
21.3 \pm 2.7 \%\end{array}$ & $\begin{aligned} 27.6 \pm 2.4 \% \\
26.8 \pm 2.4 \% \\
5.4 \pm 1.2 \% \\
10.5 \pm 1.6 \% \\
20.1 \pm 2.1 \%\end{aligned}$ \\
\hline
\end{tabular}

The differences in mean age and in the proportion of light smokers are significant at $\mathrm{P}<0.05$. 
TABLE II-Mean Levels ( \pm S.E.) of Variables in the Two Groups

\begin{tabular}{l}
\multicolumn{1}{c}{} \\
\end{tabular}

Differences between mean levels of $P-R$ and proportions with extrasystoles differ significantly at $P<0.05$.

\section{Discussion}

An aspect of this study which requires careful consideration is the sensitivity of the various comparisons made. This can be judged from the sizes of the standard errors (S.E.) shown in Tables I and II. These indicate that for each of the variables a difference which is smaller than that likely to be clinically important would have been detected as statistically significant at conventional levels (twice the S.E. of the difference between the two means). Thus for blood pressure differences in means of more than $3.6 \mathrm{~mm}$ systolic or $2.3 \mathrm{~mm}$ diastolic, or a difference greater than $6.5 \mathrm{mg}$ of cholesterol, would be statistically significant at $P<0.05$. All these differences, and those for the other variables, are acceptably small.

The few differences which have been detected at $\mathrm{P}<0.05$ are difficult to interpret. There is a significant difference in mean age $(2 \cdot 1$ years $)$ but this is very small and unlikely to be important in the overall comparisons presented. In any case the data were analysed within three age groups separately and the conclusions which follow are based on this more detailed examination. The significant difference in mean P-R duration is of interest as it is consistent within the three age groups, but its clinical importance is unknown. The increased proportion of men with extrasystoles of ventricular origin in hard water areas is statistically significant but is not consistent in direction within the three age groups examined. A measurement based on a short E.C.G. run is unlikely to be reliable either for an individual or for a group, but, nevertheless, the presence of ventricular extrasystoles in a routine E.C.G. has been shown to indicate an increased mortality risk (Chiang, Perlman, Ostrander, and Epstein, 1969). The higher prevalence of angina in the hard water area, though not significant, is also of interest, as it is inconsistent with a lower mortality in these areas. However, hardness of water appears to be relevant to the process of infarction rather than to the development of arteriosclerosis (Crawford and Crawford, 1967). The Q-T interval in the two groups is identical, even when examined as a regression on $R-R$. This is of interest, as a prolongation of this interval is associated with sudden death (James, 1969).

It is perhaps more important, however, to stress the absence in these data of differences in most variables which are statistically or clinically important. While they cannot rule out, with absolute certainty, any of the possible mechanisms by which water affects mortality, they do indicate areas into which future investigations may most profitably be directed.

\section{References \\ ${ }^{1}$ Begg, T. B., Wade, I. M., and Bronte-Stewart, B. (1966). Fournal of Atherosclerosis Research, 6, 303. \\ Chiang, B. N., Perlman, L. V., Ostrander, L. D., jun., and Epstein, F. H. (1969). Annals of Internal Medicine, 70, 1159. \\ ${ }^{3}$ Crawford, M. D., Gardner, M. J., and Morris, J. N. (1968). Lancet, $1,827$. \\ Crawford, T., and Crawford, M. D. (1967). Lancet, 1, 229. \\ 5 Davies, D. F. (1958). Clinical Science, 17, 563. \\ - Hart, J. T. (1970). Fournal of the Royal College of General Practitioners, $19,258$. \\ 7 James, T. N. (1969). Modern Concepts of Cardiovascular Disease, 38, 35. \\ Khosla, T., and Lowe, C. R. (1967). British fournal of Preventive and Social Medicine, 21, 122 . \\ - Kobayashi, J. (1957). Bericht des Ohara Instituts für landwirtschaftliche Biologie, 11, 12 . \\ ${ }^{10}$ Rose, G. A. (1962). Bulletin of the World Health Organization, 27, 645. \\ 1 Schroeder, H. (1960). Fournal of the American Medical Association, $172,1902$.}

Medical Research Council, London W1N 4AL

RODNEY SWEETNAM, F.R.c.s., Orthopaedic Surgeon, Middlesex Hospital, London W.1

JOHN KNOWELDEN, M.D., M.R.C.P., Professor of Preventive Medicine and Public Health, University of Sheffield

SIR HERBERT SEDDON, C.M.G., D.M., F.R.C.S., Honorary Consultant Surgeon, Royal National Orthopaedic Hospital, London WIN 6AD prospective study. Of the 192 patients available for the comparison, those treated by radiotherapy alone did least well. A combination of the two treatmentsradiotherapy followed by amputation-produced better results, in terms of survival, than amputation alone; however, the comparatively small numbers involved and the inadequacy of information about the factors dictating the choice of treatment make firm conclusions impossible. A controlled clinical trial on a larger scale might provide answers to the outstanding questions.

\section{Introduction}

The efficacy of any form of treatment of osteosarcoma has always been low, and the rarity of the disease has hindered the collection of sufficient information on which to base an evaluation of the respective merits of surgery, radiotherapy, and a combination of the two forms of treatment. The M.R.C. 